\title{
Credit financing in economic ordering policies for non-instantaneous deteriorating items with price dependent demand under permissible delay in payments: A new approach
}

\author{
Chandra K. Jaggi*, Anuj Sharma and Sunil Tiwari
}

Department of Operational Research, Faculty of Mathematical Sciences, New Academic Block, University of Delhi, Delhi 110007, India

\begin{tabular}{l}
\hline C H R O N I C L E \\
\hline Article history: \\
Received January 162015 \\
Received in Revised Format \\
April 102015 \\
Accepted May 182015 \\
Available online \\
May 182015 \\
\hline Keywords: \\
Inventory \\
Permissible delay in payments \\
Non-instantaneous deteriorates \\
items \\
Triangular fuzzy number \\
Function principle and signed \\
distance method
\end{tabular}

\section{Introduction}

In today's competitive markets, trade credit is an increasingly important payment behavior in real business transactions. Trade credit management needs to balance the trade-off between increased sales and the risk of granting credit. By providing trade credit, a supplier can maintain a long-term relationship with a retailer to enhance the competitiveness of their supply chain. In practice, a supplier usually provides her/his retailers a permissible delay in payments to stimulate sales and reduce inventory. However, in the inventory models developed, it is often assumed that payment will be made to the supplier for the goods immediately after receiving the consignment. Because the permissible delay in payments can provide economic sense for vendors, it is possible for a supplier to allow a certain credit * Corresponding author. TelFax: 91-11-27666672

E-mail: ckjaggi@yahoo.com (C. K. Jaggi)

(c) 2015 Growing Science Ltd. All rights reserved. doi: $10.5267 /$ j.jijiec.2015.5.003

\begin{abstract}
In the existing literature of inventory modeling under the conditions of permissible delay in payments, researchers have assumed that the retailers have to settle their accounts at the end of credit period i.e. supplier accept only full amount at the end of the credit period. However in reality, supplier may either accept the partial amount at the end of the credit period and unpaid balance subsequently or the full amount at a fix point of time after the expiry of the credit period, if the retailer finances the inventory from the supplier itself. Further, in the classical deteriorating inventory models, the common unrealistic assumption is that all the items start to deteriorate as soon as they arrive in the system. However, in realistic environment, it is observed that there are several non-instantaneous deteriorating items that have a shelf life and start to deteriorate after a time lag, like dry fruits, potatoes, yams and even some fruits and vegetables etc. Considering the importance of above mentioned facts, the present study formulates a fuzzy inventory model for non-instantaneous deteriorating items under conditions of permissible delay in payments. The paper discusses all the possible cases which may arise and yet not considered in the previous inventory models under permissible delay in payments. Further, this paper also considers pricedependent demand and the possibility of higher interest earn rate than interest payable rate. The objective of this study is to determine the optimal decision policies for the retailer which maximizes the total profit. Finally, the numerical examples are solved by using the proposed algorithm to show the validity of the model followed by the sensitivity analysis.
\end{abstract}


period for buyers to stimulate the demand to maximize the vendors-owned benefits and advantage. Recently, several researchers have developed analytical inventory models with consideration of permissible delay in payments. Haley and Higgins (1973) developed the economic order quantity model under the condition of permissible delay in payments with deterministic demand, without shortages and zero lead time. Goyal (1985) extended their model with the exclusion of the penalty cost due to a late payment. Shah (1993), Aggarwal and Jaggi (1995) and Hwang and Shinn (1997) extended Goyal's (1985) model by incorporating the case of deterioration. Jamal et al. (1997) extended Aggarwal and Jaggi (1995) model to allow for shortages. Jaggi et al. (2008) determined a retailer's optimal replenishment decisions with trade credit-linked demand under permissible delay in payments. Recently, Cheng et al. (2012) discussed an economic order quantity model with trade credit policy in different financial environments. They discussed the model under the condition that the interest earned rate can be higher than the interest charged rate. Other inventory works in this area are summarized by different survey papers (Chang et al., 2008; Soni et al., 2010; Seifert et al., 2013; Molamohamadi et al., 2014).

In the above mention papers of inventory modeling under the conditions of permissible delay in payments, researchers have assumed that the retailers have to settle their accounts at the end of credit period i.e. supplier accept only full amount at the end of the credit period. However in reality, supplier may either accept the partial amount at the end of the credit period and unpaid balance subsequently or the full amount at a fix point of time after the expiry of the credit period, if the retailer finances the inventory from the supplier itself. All the possible cases which may arise are considering in this model.

Non-instantaneous deteriorating item means that an item maintains its quality or freshness for some extent of time and losses the usefulness from the original condition, subsequently. The models are very useful for non-instantaneous deteriorating items such as fresh food and fruits. Wu et al. (2006) first introduced the phenomenon "non-instantaneous deterioration" and established the optimal replenishment policy for non-instantaneous deteriorating item with stock dependent demand and partial backlogged shortages. Ouyang et al. (2006) developed an inventory model for non-instantaneous deteriorating items under trade credits. Geetha and Uthayakumar (2010) extended Ouyang et al. (2006)'s model incorporating time-dependent backlogging rate. Other related work in this area are Ouyang et al. (2006), Ouyang et al. (2008), Chung (2009), Wu et al. (2009), Jaggi and Verma (2010), Chang et al. (2010), Geetha et al. (2010), Soni et al. (2012), Maihami and Kamalabadi (2012a, 2012b), Shah et al. (2013), Dye and Hsieh (2012). Dye and Hsieh (2013) considered different inventory problems for noninstantaneous deteriorating items.

According to the modern view, uncertainty is considered essential to science; it is not only an unavoidable phenomenon but has, in fact, a great utility in real world applications. Although the inventory cost parameters in the above mentioned studies are assumed to be crisp and precise, in real world problems they are uncertain, since they depend on different factors. To cope with the mentioned uncertainty in inventory models' parameters and imprecise information in decision making, the notion of fuzziness, which was introduced by Zadeh (1965), is an appropriate approach for considering the vagueness. Further, estimation of parameters in the demand and cost functions using traditional econometrics methods is not always possible. In many cases if there are no historical data to estimate the demand especially for new product launched, the concept of fuzzy set theory is the best approach in these cases. A discussion on attempts by various investigators to study and optimize fuzzy inventory models is presented next. Zimmermann (1985) gave a review on applications of fuzzy set theory. Park (1987) used fuzzy set concepts to treat the inventory problem with fuzzy inventory cost under the arithmetic operations defined by extension principle. He examined the EOQ model using the fuzzy set theoretic perspective. Kauffmann and Gupta (1991) provided an introduction to fuzzy arithmetic operation. Kacprzyk and Staniewski (1982) applied the fuzzy set theory to inventory control problem and considered a long term inventory policy making through fuzzy decision models. Inventory control by optimal policies for controlling cost rates in a fluctuating demand environment was investigated by Song and Zipkin (1993). Vujosevic et al. (1996) extended the classical EOQ model by introducing the 
fuzziness of ordering cost and holding cost. Roy and Maiti (1997) presented a fuzzy EOQ model with demand-dependent unit cost under limited storage capacity considering different parameters as fuzzy sets with suitable membership function. Kao and Hsu (2002), Dutta, Chakraborty, and Roy (2005) studied single period inventory model with fuzzy demand and fuzzy random variable demand, respectively, and developed models for optimum order quantity in terms of cost. Syed and Aziz (2007) modeled inventory model without shortage under fuzzy environment. Ordering and holding costs were considered as fuzzy triangular numbers, and optimum order quantity was developed using signed distance method. Wang et al. (2007) developed the model of fuzzy economic order quantity without backordering. Holding cost and set-up cost were considered as fuzzy in nature and the model was developed for keeping the credibility of total cost in the planning period below certain budget level. Vijayan and Kumaran (2008) investigated continuous review and periodic review inventory models under fuzzy environment, where the membership function distribution took a trapezoidal form. Gani and Maheswari (2010) discussed the retailer's ordering policy under two levels of delay payments considering the demand and the selling price as triangular fuzzy numbers. They used graded mean integration representation method for defuzzification. Singh et al. (2011) and Malik and Singh (2011) utilized soft computing techniques for modeling of inventory under price dependent demand and variable demand, respectively. In the same year, Mahata and Mahata (2011) applied fuzzy EOQ model to supply chains and Rong (2011) developed EOQ model by treating the holding cost, shortage cost and ordering cost per unit as uncertain variables.

Based on above mentioned situations, this paper considers the retailer's optimal policy for noninstantaneous deteriorating items with permissible delay in payments under different scenarios in fuzzy environment. The paper discusses all the possible cases which may arise and yet not considered in the previous inventory models under permissible delay in payments. Further, this paper also considers the price dependent demand and the possibility of higher earning interest rate than interest payable. The components of demand function are assumed as triangular fuzzy number. The arithmetic operations are defined under the function principle and for defuzzification, signed distance method is employed to evaluate the optimal cycle length $T$, markup rate and payoff time which maximize the total profit in all possible cases. Finally, numerical examples are presented to show the validity of the model followed by the sensitivity analysis. Results have shown significant effect in real life.

\section{Preliminaries}

This model is formulated in fuzzy environment with help of following definitions.

Definition 2.1: A fuzzy set $\tilde{k}$ on $R=(-\infty, \infty)$ is called a fuzzy point if its membership function is

$$
\mu_{\tilde{k}}(x)=\left\{\begin{array}{c}
1, x=k \\
0, x \neq k
\end{array}\right\},
$$

where the point $k$ is called the support of fuzzy set $\tilde{k}$

Definition 2.2 A fuzzy set $\left[k_{\alpha}, l_{\alpha}\right]$ where $0 \leq \alpha \leq 1$ and $k<l$ defined on $R$, is called a level of a fuzzy interval if its membership function is

$$
\mu_{\left[k_{\alpha}, l_{\alpha}\right]}(x)=\left\{\begin{array}{l}
\alpha, k \leq x \leq l \\
0, \text { otherwise }
\end{array}\right\}
$$

Definition 2.3 A fuzzy number $\tilde{K}=\left(k_{1}, k_{2}, k_{3}\right)$ where $k_{1}<k_{2}<k_{3}$ and defined on $R$, is called a triangular fuzzy number if its membership function is 
$\mu_{\tilde{K}}(x)=\left\{\begin{array}{l}\frac{x-k_{1}}{k_{2}-k_{1}}, k_{1} \leq x \leq k_{2} \\ \frac{k_{3}-x}{k_{3}-k_{2}}, k_{2} \leq x \leq k_{3} \\ 0, \text { Otherwise }\end{array}\right.$

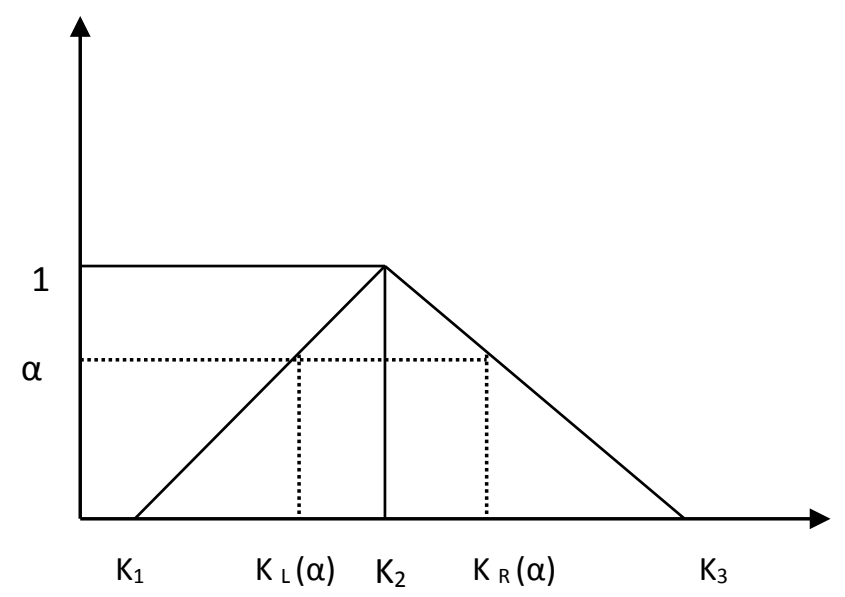

Fig. 1. $\alpha$-cut of a triangular fuzzy number

When $k_{1}=k_{2}=k_{3}=k$, we have fuzzy point $(k, k, k)=\tilde{k}$.

The family of all triangular fuzzy numbers on $R$ is denoted as $F_{N}=\left\{\left(k_{1}, k_{2}, k_{3}\right) \mid k_{1}<k_{2},<k_{3} \forall k_{1}, k_{2}, k_{3} \in R\right\}$

The $\alpha$-cut of $\tilde{K}=\left(k_{1}, k_{2}, k_{3}\right) \in F_{N}, 0 \leq \alpha \leq 1$, is $K(\alpha)=\left[K_{L}(\alpha), K_{R}(\alpha)\right]$,

where $K_{L}(\alpha)=k_{1}+\left(k_{2}-k_{1}\right) \alpha$ and $K_{R}(\alpha)=k_{3}-\left(k_{3}-k_{2}\right) \alpha$ are the left and right endpoints of $K(\alpha)$.

Definition 2.4 If $\tilde{K}=\left(k_{1}, k_{2}, k_{3}\right)$ is a triangular fuzzy number then the signed distance form $\tilde{K}$ to 0 is defined as

$d(\tilde{K} \tilde{0})=\int_{0}^{1} d\left(\left[k_{L}(\alpha)_{\alpha}, K_{R}(\alpha)_{\alpha}\right], \tilde{0}\right)=\frac{1}{4}\left(k_{1}+2 k_{2}+k_{3}\right)$

\section{Assumptions and Notations}

The following notations and assumptions have been used in developing the model.

\subsection{Notations}

$\begin{array}{ll}I(t) & : \text { instantaneous inventory level at time } t \\ Q & : \text { order level } \\ D(p)=D=a-b p & : \text { price dependent demand } \\ \tilde{D}(p)=\tilde{D}=\tilde{a}-\tilde{b} p & : \text { fuzzy price dependent demand } \\ A & : \text { replenishment cost (ordering cost) for replenishing the items } \\ c & : \text { unit purchase cost of retailer } \\ h & : \text { holding cost per unit per unit time excluding interest charge } \\ \theta & : \text { deterioration rate and } 0 \leq \theta<1 \\ \mu(\mu>1) & : \text { mark up rate }\end{array}$




$\begin{array}{ll}p=\mu c & : \text { selling price per unit } \\ M & : \text { credit period offered by the supplier } \\ I_{e} & : \text { interest earned by the retailer (\$ per year) } \\ I_{p} & : \text { interest payable to the supplier (\$ per year) } \\ t_{d} & : \text { time period during which no deterioration occurs. } \\ T & : \text { replenishment cycle length } \\ B_{i} & : \text { breakeven point, } i=1,2,3 \\ A P_{(.)}(\mu, T) & : \text { total profit in case }(.) \\ A P(.) & : \text { total profit in combine form for all cases } \\ A P_{d}(.) & : \text { total profit after defuzzify }\end{array}$

\subsection{Assumptions}

(i) Replenishment rate is infinite and lead time is negligible.

(ii) The inventory planning horizon is infinite and the inventory system involves only single commodity and single stocking point.

(iii) The entire lot size is delivered in one batch.

(iv) Shortages are not allowed.

(v) Demand rate is assumed to be a function of selling price i.e. $D(p)=a-b p$ which is a function of selling price $(p)$, where $a, b$ are positive constants and $0<b<a / p$. Further, $a \& b$ are assumed as triangular fuzzy number.

\section{Model Formulation}

This is an EOQ model for a single non-instantaneous deteriorating item with permissible delay in payments. Initially, a lot size of $Q$ units enters the inventory system and depletes due to demand in the interval $\left[0, t_{d}\right]$. After that i.e. in the time interval $\left[t_{d}, T\right]$ this is deplete due to the combine effect demand and deterioration. At $t=T$, the inventory stock is exhausted. At any time $t$ the inventory level can be shown by following differential equation.

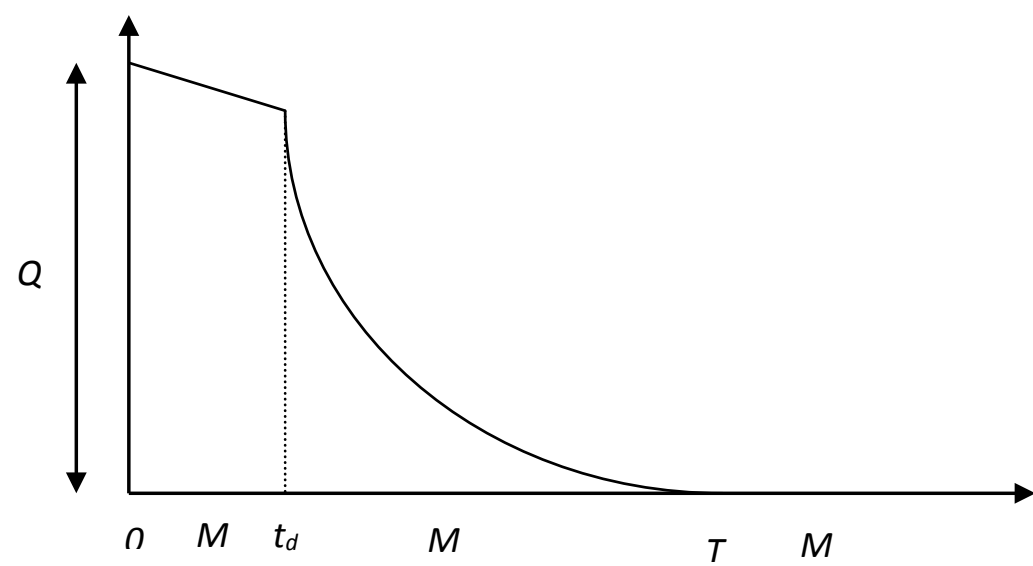

Fig. 2. Inventory level at any time

$$
\begin{array}{cr}
\frac{d I(t)}{d t}=D, & 0 \leq t \leq t_{d} \\
\frac{d I(t)}{d t}+\theta I(t)=-D, & t_{d}<t \leq T
\end{array}
$$


These differential equations solve with using boundary conditions $I(0)=Q$, and $I(T)=0$ respective are as follows:

$$
\begin{array}{crl}
I(t)=Q-D t, & 0 & \leq t \leq t_{d} \\
I(t)=\frac{D}{\theta}\left(e^{\theta(T-t)}-1\right), & t_{d} & <t \leq T
\end{array}
$$

For continuity of $I(t)$ at $t=t_{d}$, it follows from Eq. (3) and Eq. (4) that

$$
Q-D t_{d}=\frac{D}{\theta}\left(e^{\theta\left(T-t_{d}\right)}-1\right)
$$

This implies that the maximum inventory level per cycle is

$$
Q=D\left(t_{d}+\frac{1}{\theta}\left(e^{\theta\left(T-t_{d}\right)}-1\right)\right)
$$

The number of deteriorated unit $Q-D T$ is

$$
=D\left(t_{d}-T+\frac{1}{\theta}\left(e^{\theta\left(T-t_{d}\right)}-1\right)\right)
$$

Now, the profit function per unit time can be expressed as $A P(\mu, T)=\frac{1}{T}[<$ Total selling revenue $>+<$ Interest earned $>-<$ Total purchase cost $>-$

where

$$
<\text { Ordering Cost }>\text { - < Holding Cost }>\text { - < Interest paid }>\text { ] }
$$

a) Ordering cost per cycle $=A$

b) The inventory holding cost per cycle $=h\left(\int_{0}^{t_{d}} I(t) d t+\int_{t_{d}}^{T} I(t) d t\right)$

$$
=h\left\{\frac{D t_{d}^{2}}{2}+\frac{D}{\theta^{2}}\left(e^{\theta\left(T-t_{d}\right)}-1\right)\left(\theta t_{d}+1\right)-\left(T-t_{d}\right)\right\}
$$

c) The purchase cost per cycle $=c Q$

$$
=c D\left(t_{d}+\frac{1}{\theta}\left(e^{\theta\left(T-t_{d}\right)}-1\right)\right)
$$

d) The Sales Revenue per cycle $=D T p$

For the calculation of interest earned and payable, two possible cases depending on the values of interest earned and payable rate i.e. $I_{e}<I_{p}$ and $I_{e} \geq I_{p}$ arises. These two cases have been discussed in following two sections.

Section 1: $I_{e}<I_{p}$

In this section, the interest earned rate $\left(I_{e}\right)$, is assumed to be less than the interest payable rate $\left(I_{p}\right)$. Further, depending upon values of $M, t_{d}$ and $T$ there can be three possible cases:

Case 1.1: $0<M \leq t_{d}<T$, Case 1.2: $0<t_{d}<M \leq T$ and Case 1.3: $0<t_{d}<T<M$

Case 1.1: $0<M \leq t_{d}<T$

In this case, the retailer tries to pay off the total purchase cost to the supplier as soon as possible. Therefore, up to time period $M$, the total sales revenue generated by the retailer is $D M p$ and he also earns interest on this sales revenue which is $\frac{1}{2} D M^{2} p I_{e}$. 
Hence, the total amount available at time $M$ is sum of sales revenue and interest earned on regular sales revenue i.e.

$$
D M p+\frac{1}{2} D M^{2} p I_{e} \equiv W \text { (say) }
$$

At this point of time, retailer wishes to settle his account with the supplier. Which gives birth to another two sub-cases viz. $W<Q c$ and $W \geq Q c$.

Sub case 1.1.1: $W<Q c$

Here, the retailer's sales proceeds $(W)$ is less than the amount payable $(Q c)$ to the supplier. In this situation, supplier may either agree to receive the partial payment or not. Thus, further two scenarios generated i.e. when partial payment is acceptable at $M$ and the rest amount is to be paid any time after $\mathrm{M}$ and when partial payment is not acceptable at $M$ but the full payment is acceptable by the supplier any time after $M$.

Scenario 1.1.1.1: When partial payment is acceptable at $M$ and the rest amount is to be paid any time after $M$. This scenario is further divided into two situations i.e.

(a) When the rest amount continuously is paid after $M$ and

(b) When the rest amount is paid as a single installment any time after $M$.

Scenario1.1.1.1 (a): When the rest amount is paid continuously up to breakeven point $B_{1}$ (say) after $M$

In this scenario, the retailer pays $W$ amount at $M$ and the rest amount $(c Q-W)$ along with the interest charged will be paid continuously from $M$ to some payoff time $B_{1}$ (says).

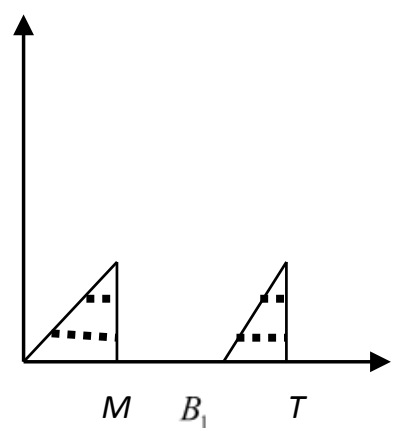

Fig. 3. Interest earned in scenario 1.1.1.1. (a)

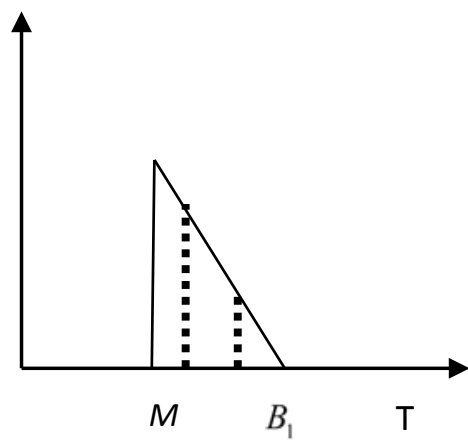

Fig. 4. Interest payable in scenario 1.1.1.1. (a)

The interest payable during the period $\left[M, B_{1}\right]=\frac{1}{2}(c Q-W)\left(B_{1}-M\right) I_{p}$ and

The total amount payable during $\left[M, B_{1}\right]=(c Q-W)+\frac{1}{2}(c Q-W)\left(B_{1}-M\right) I_{p}$

$\Rightarrow$ At $t=B_{1}$, the total amount payable to the supplier = the total amount available to the retailer

$$
\begin{gathered}
\Rightarrow(c Q-W)+\frac{1}{2}(c Q-W)\left(B_{1}-M\right) I_{p}=D\left(B_{1}-M\right) p \\
\Rightarrow \quad B_{1}=M+\frac{2(c Q-W)}{2 D p-(c Q-W) I_{p}}
\end{gathered}
$$


Now, from time $\left(B_{1}\right)$ onwards the retailer starts accumulating profit from the sales and earns interest during the period $\left[B_{1}, T\right]$

The total sales revenue $=D\left(T-B_{1}\right) p$ and

Interest earned $=\frac{1}{2} D\left(T-B_{1}\right)^{2} p I_{e}$.

Therefore, the total profit per unit time for this case is given by

$A P_{1.1 .1 .1 .(a)}(\mu, T)=\frac{1}{T}\left[<\right.$ Total selling revenue during $\left[B_{1}, T\right]>+<$ Interest earned during $\left[B_{1}, T\right]>-$

$<$ Ordering Cost $>-<$ Holding Cost $>$ ]

$A P_{1.1 .1 .1(a)}(\mu, T)=\frac{1}{T}\left[D\left(T-B_{1}\right) p+\frac{1}{2} D\left(T-B_{1}\right)^{2} p I_{e}-A-h\left\{\frac{D t_{d}^{2}}{2}+\frac{D}{\theta^{2}}\left(e^{\theta\left(T-t_{d}\right)}-1\right)\left(\theta t_{d}+1\right)-\left(T-t_{d}\right)\right\}\right]$

Where $B_{1}=M+\frac{2(c Q-W)}{2 D p-(c Q-W) I_{p}}$

\section{Scenario 1.1.1.1(b): When the rest amount is paid at a breakeven point $B_{2}$ (say) after $M$}

In this scenario, supplier accepts the payment only on two installments first is at time $M$ and second is at some payoff time $B_{2}$ (says). The retailer pays amount $W$ at $M$ and the rest amount $(c Q-W)$ along with the interest charged will be paid at a breakeven point $B_{2}$. Now, at time $t=B_{2}$, retailer would generate an amount of $D\left(B_{2}-M\right) p$ from sales revenue for the period $\left[M, B_{2}\right]$ and also earn interest from the continuous interest earn on the selling revenue generated during the same.

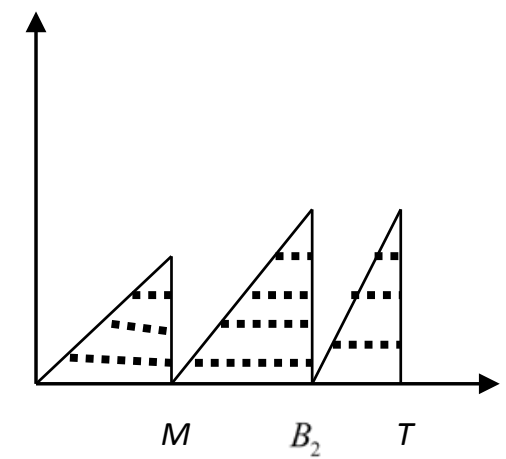

Fig. 5. Interest earned in scenario 1.1.1.1. (b)

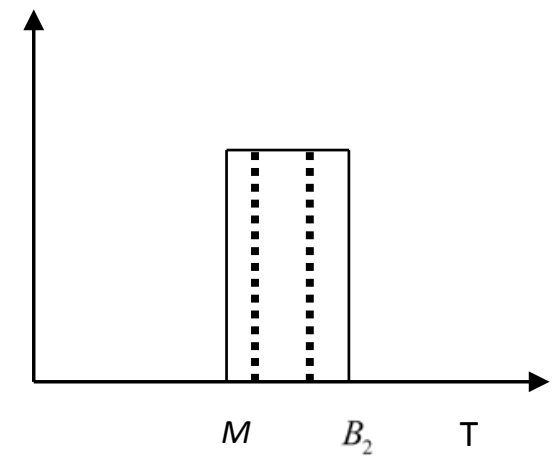

Fig. 6. Interest payable in scenario 1.1.1.1. (b)

The interest payable during the period $\left[M, B_{2}\right]=(c Q-W)\left(B_{2}-M\right) I_{p}$

The interest earned during the period $\left[M, B_{2}\right]=\frac{1}{2} D\left(B_{2}-M\right)^{2} p I_{e}$

The total amount payable at $B_{2}=(c Q-W)+(c Q-W)\left(B_{2}-M\right) I_{p}$ and

The total amount earn during the period $\left[M, B_{2}\right]=D\left(B_{2}-M\right) p+\frac{1}{2} D\left(B_{2}-M\right)^{2} p I_{e}$

$\Rightarrow$ At $t=B_{2}$, the total amount payable to the supplier = the total amount available to the retailer

$\Rightarrow(c Q-W)+(c Q-W)\left(B_{2}-M\right) I_{p}=D\left(B_{2}-M\right) p+\frac{1}{2} D\left(B_{2}-M\right)^{2} p I_{e}$ 


$$
\Rightarrow B_{2}=\frac{1}{D p I_{e}}\left\{-D p+D p I_{e} M+Q c I_{p}-I_{p} W+\left(\left(D p-Q c I_{p}+W I_{e}\right)^{2}+2 D p Q c I_{e}\right)^{\frac{1}{2}}\right\}
$$

Now, from this point onwards the retailer starts generating profit from the sales and also earns interest on the same i.e. during the period $\left[B_{2}, T\right]$

The total sales revenue $=D\left(T-B_{2}\right) p$ and Interest earned $=\frac{1}{2} D\left(T-B_{2}\right)^{2} p I_{e}$.

Therefore, the total profit per unit time for this case is given by $A P_{1.1 .1 .1(b)}(\mu, T)=\frac{1}{T}\left[<\right.$ Total selling revenue during $\left[B_{2}, T\right]>+<\operatorname{Interest~earned~during~}\left[B_{2}, T\right]>-$ $<$ Ordering Cost $>-<$ Holding Cost $>$ ]

$$
A P_{1.1 .1 .1(b)}(\mu, T)=\frac{1}{T}\left[D\left(T-B_{2}\right) p+\frac{1}{2} D\left(T-B_{2}\right)^{2} p I_{e}-A-h\left\{\frac{D t_{d}^{2}}{2}+\frac{D}{\theta^{2}}\left(e^{\theta\left(T-t_{d}\right)}-1\right)\left(\theta t_{d}+1\right)-\left(T-t_{d}\right)\right\}\right]
$$

Where $B_{2}=\frac{1}{D p I_{e}}\left\{-D p+D p I_{e} M+Q c I_{p}-I_{p} W+\left(\left(D p-Q c I_{p}+W I_{e}\right)^{2}+2 D p Q c I_{e}\right)^{\frac{1}{2}}\right\}$

\section{Scenario 1.1.1.2: When full payment is to be made at the breakeven point $B_{3}$ (say) after $M$}

In this scenario, Supplier wants the full payment at some fixed point $B_{3}$ (says) after $M$ when it is possible. Now, at time $t=M$, the retailer has $W$ amount and he will earn the interest on this amount for the period $\left[M, B_{3}\right]$, but he has to pay the interest for the time period $\left[M, B_{3}\right]$. Further, at time $t=B_{3}$, retailer would generate an amount of $D\left(B_{3}-M\right) p$ from sales revenue for the period $\left[M, B_{3}\right]$ and also earn interest from the continuous interest earn on the selling revenue generated during the same.

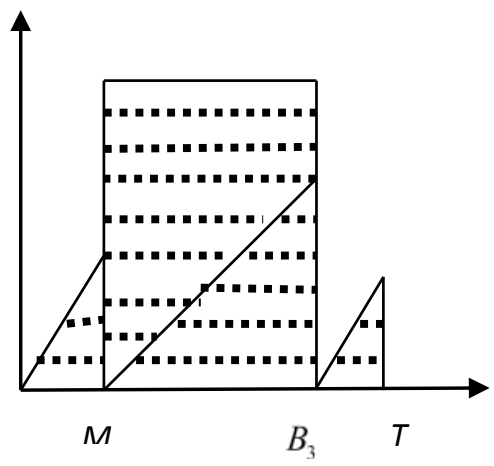

Fig. 7. Interest earned in scenario 1.1.1.2

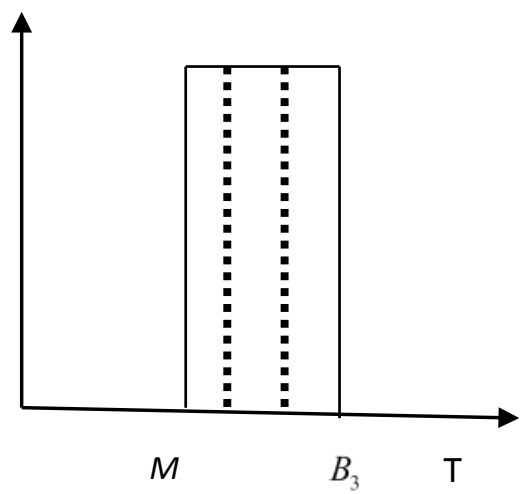

Fig. 8. Interest payable in scenario 1.1.1.2

The interest earned on accumulated amount $W$ for the time period $\left[M, B_{3}\right]=W I_{e}\left(B_{3}-M\right)$

The interest earned on the continuous sales revenue from time period $\left[M, B_{3}\right]=\frac{1}{2} D\left(B_{3}-M\right)^{2} p I_{e}$.

Hence, the total interest earned during the time period $\left[M, B_{3}\right]=$

$W I_{e}\left(B_{3}-M\right)+\frac{1}{2} D\left(B_{3}-M\right)^{2} p I_{e}$

The total amount available to the retailer at 


$$
B_{3}=W+D\left(B_{3}-M\right) p+W I_{e}\left(B_{3}-M\right)+\frac{1}{2} D\left(B_{3}-M\right)^{2} p I_{e}
$$

The interest payable during the period $\left[M, B_{3}\right]=Q c I_{p}\left(B_{3}-M\right)$ and

The total amount payable at $B_{3}=Q c+Q c I_{p}\left(B_{3}-M\right)$

$\Rightarrow$ At $t=B_{3}$, the total amount payable to the supplier $=$ the total amount available to the retailer

$$
\begin{aligned}
& Q c+ Q c\left(B_{3}-M\right) I_{p}=W+D\left(B_{3}-M\right) p+W I_{e}\left(B_{3}-M\right)+\frac{1}{2} D\left(B_{3}-M\right)^{2} p I_{e} \\
&\left.\Rightarrow B_{3}=\frac{1}{D p I_{e}}\left\{-D p+D p I_{e} M+Q c I_{p}-I_{e} W+\left(\left(W I_{e}-Q c I_{p}+D p\right)\right)^{2}+2 D p Q c I_{e}\right)^{\frac{1}{2}}\right\}
\end{aligned}
$$

Now, from this point onwards the retailer starts generating profit from the sales and also earns interest on the same i.e. during the period $\left[B_{3}, T\right]$

The total sales revenue during the time period $\left[B_{3}, T\right]=D\left(T-B_{3}\right) p$ and

The interest earned during same period $=\frac{1}{2} D\left(T-B_{3}\right)^{2} p I_{e}$.

Therefore, the total profit per unit time for this case is given by $A P_{1.1 .1 .2}(\mu, T)=\frac{1}{T}\left[<\right.$ Total sales revenue during $\left[B_{3}, T\right]>+<\operatorname{Interest~earned~during~}\left[B_{3}, T\right]>-$

$<$ Ordering Cost $>$ - < Holding Cost $>$ ]

$$
A P_{1.1 .1 .2}(\mu, T)=\frac{1}{T}\left[D\left(T-B_{3}\right) p+\frac{1}{2} D\left(T-B_{3}\right)^{2} p I_{e}-A-h\left\{\frac{D t_{d}^{2}}{2}+\frac{D}{\theta^{2}}\left(e^{\theta\left(T-t_{d}\right)}-1\right)\left(\theta t_{d}+1\right)-\left(T-t_{d}\right)\right\}\right]
$$

Where $\left.B_{3}=\frac{1}{D p I_{e}}\left\{-D p+D p I_{e} M+Q c I_{p}-I_{e} W+\left(\left(W I_{e}-Q c I_{p}+D p\right)\right)^{2}+2 D p Q c I_{e}\right)^{\frac{1}{2}}\right\}$

\section{Sub case 1.1.2: $W \geq Q c$}

In this sub case, retailer has to pay only $Q c$ amount to the supplier at time $M$, he will earn the interest on the excess amount $(W-Q c)$ for the time period $[M, T]$. Further, after time $t=M$, the retailer continuously sales the products and uses the revenue to earn interest.

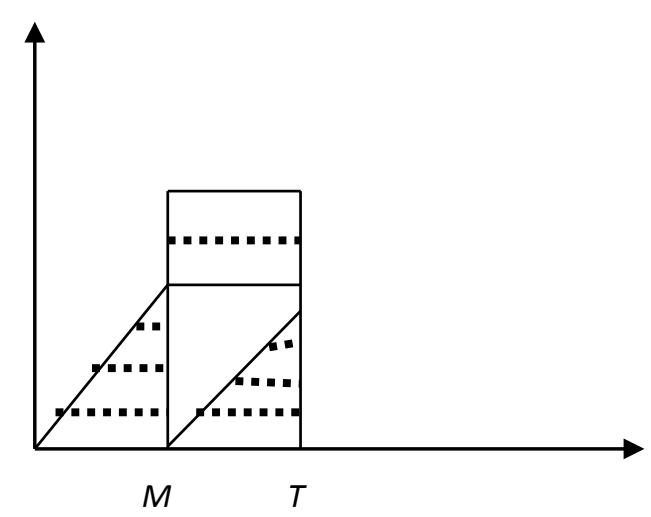

Fig. 9. Interest earned in sub case 1.1.2

The interest earned on the excess amount $(W-Q c)$ for the period $[M, T]=(W-Q c)(T-M) I_{e}$ 
The interest earned on the sales revenue during the period $[M, T]=\frac{1}{2} D(T-M)^{2} p I_{e}$

Therefore, the total profit per unit time for this case is given by

$A P_{1.1 .2}(\mu, T)=\frac{1}{T}[<$ Total sales revenue during $[M, T]>+<$ Interest earned on the sales revenue

during $[M, T]>+<$ Remaining excess amount after paying the amount to the supplier $>+$ $<$ Interest earned on the excess amount during $[M, T]>-<$ Ordering Cost $>-<$ Holding Cost>]

$$
A P_{1.1 .2}(\mu, T)=\frac{1}{T}\left[D(T-M) p\left\{1+\frac{1}{2}(T-M) I_{e}\right\}+(W-Q C)\left\{1+(T-M) I_{e}\right\}-A-h\left\{\frac{D t_{d}^{2}}{2}+\frac{D}{\theta^{2}}\left(e^{\theta\left(T-t_{d}\right)}-1\right)\left(\theta t_{d}+1\right)-\left(T-t_{d}\right)\right\}\right]
$$

Case 1.2: $0<t_{d}<M \leq T$

In this case, permissible delay period $M$ lies between the time $t_{d}$ at which deterioration start and replenishment cycle time $T$. In this case the mathematical formulation is same as of Case 1.1 i.e. $0<M \leq t_{d}<T$. So the mathematically formulation for this case is not necessitate.

Case 1.3: $0<t_{d}<T<M$

In this case, permissible delay period $M$ is greater than the replenishment cycle time $T$. The retailer will pay off the total amount owed to the supplier at the end of the trade credit period $M$. Therefore, there is no interest payable to the supplier but the retailer uses the sales revenue to earn interest at the rate of $I_{e}$ during the period $[0, M]$.

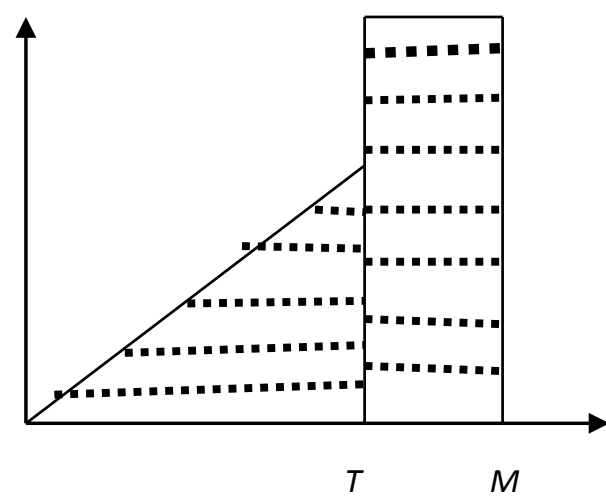

Fig. 10. Interest earned in case 1.3

The interest earned during the period $[0, T]=\frac{1}{2} D T^{2} p I_{e}$ and

The interest earned during the period $[T, M]=D T p\left(1+\frac{1}{2} T I_{e}\right) I_{e}(M-T)$

Therefore, the total profit per unit time for this case is given by $A P_{1.3}(\mu, T)=\frac{1}{T}[<$ Total sales revenue during $[0, T]>+<$ Interest earned on sales revenue during $[0, M]>-<$ Purchasing cost $>-<$ Ordering cost $>-<$ Holding cost $>]$

$$
A P_{1.3}(\mu, T)=\frac{1}{T}\left[(D T p-Q c)+\frac{1}{2} D T^{2} p+D T p\left(1+\frac{1}{2} T I_{e}\right) I_{e}(M-T)-A-h\left\{\frac{D t_{d}^{2}}{2}+\frac{D}{\theta^{2}}\left(e^{\theta\left(T-t_{d}\right)}-1\right)\left(\theta t_{d}+1\right)-\left(T-t_{d}\right)\right\}\right]
$$

Section 2: $I_{e} \geq I_{p}$ 
Here, the interest earned $I_{e}$, is taken to be greater than and equal to the interest charges $I_{p}$. Further, depending upon values of $M, t_{d}$ and $T$ there may arise three possible cases as follows:

Case 2.1: $0<M \leq t_{d}<T$ and Case 2.2: $0<t_{d}<M \leq T$ Case 2.3: $0<t_{d}<T<M$

Case 2.1: $0<M \leq t_{d}<T$

In this scenario, retailer would make the payment at $T$ not at $M$. Since $I_{e} \geq I_{p}$, the retailer never pays any amount to the supplier before the end of cycle $(T)$.

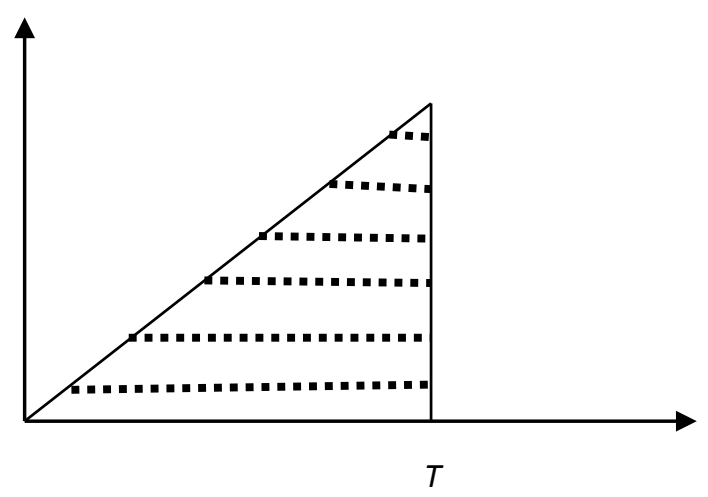

Fig. 11. Interest earned in case 2.1

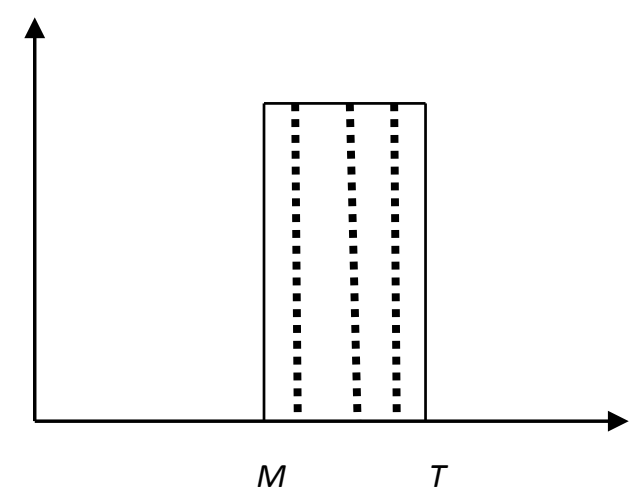

Fig. 12. Interest payable in case 2.1

The total interest payable in one cycle $=Q_{c}(T-M) I_{p}$ and

The total interest earned in one cycle after $M=W I_{e}(T-M)+\frac{1}{2} D(T-M)^{2} p I_{e}$

Hence, the total amount payable by the retailer at $T=Q c\left(1+(T-M) I_{p}\right)$

Therefore, the total profit for the cycle for this case is given by $A P_{2.1}(\mu, T)=\frac{1}{T}[<$ Total selling revenue during $[0, T]>+<$ Interest earned on the sales revenue during $[0, T]>-<$ total amount paid as well as interest payable at $T>-<$ Ordering Cost $>$ $-<$ Holding Cost $>$ ]

$$
A P_{2.1}(\mu, T)=\frac{1}{T}\left[(D T p-Q c)+\frac{1}{2} D M^{2} p I_{e}+W I_{e}(T-M)+\frac{1}{2} D p(T-M)^{2} I_{e}-Q c(T-M) I_{p}-A-h\left\{\frac{D t_{d}^{2}}{2}+\frac{D}{\theta^{2}}\left(e^{\theta\left(T-t_{d}\right)}-1\right)\left(\theta t_{d}+1\right)-\left(T-t_{d}\right)\right\}\right]
$$

Case 2.2: $0<t_{d}<M \leq T$

In this case, the mathematical expression of total profit per unit time $A P_{2.2}(\mu, T)$ is same as of in case (2.1).

Case 2.3: $0<t_{d}<T<M$

The mathematical expression of total profit per unit time $A P_{2.3}(\mu, T)$ is also same as of in case (1.3). Hence, the total profit per unit time $A P(\mu, T)$ for the inventory system can be expressed as 


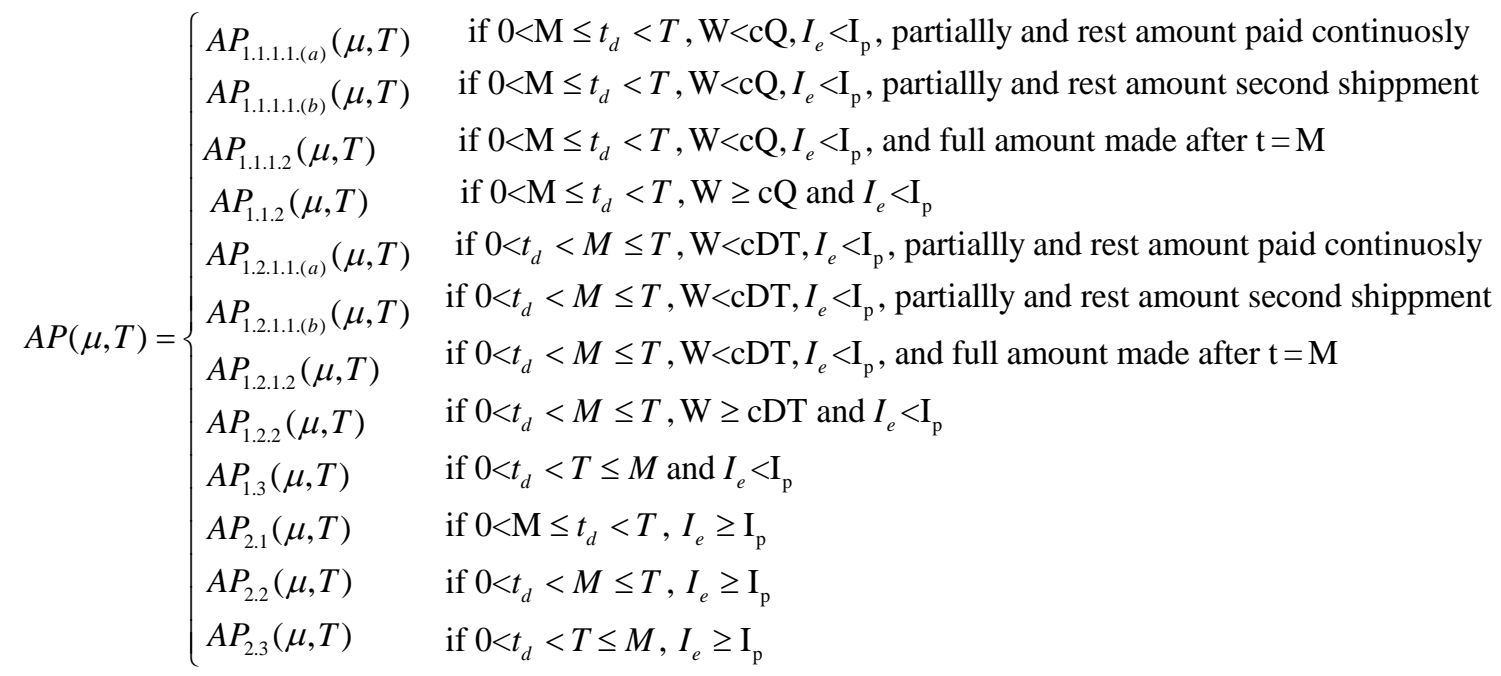

For the convenience, we let the twelve events as

$$
\begin{aligned}
& E_{1}=\left\{T \mid 0<\mathrm{M} \leq t_{d}<T, \mathrm{~W}<\mathrm{cQ}, I_{e}<\mathrm{I}_{\mathrm{p}}, \text { partiallly and rest amount paid continuosly }\right\} \\
& E_{2}=\left\{T \mid 0<\mathrm{M} \leq t_{d}<T, \mathrm{~W}<\mathrm{cQ}, I_{e}<\mathrm{I}_{\mathrm{p}}, \text { partiallly and rest amount second shippment }\right\} \\
& E_{3}=\left\{T \mid 0<\mathrm{M} \leq t_{d}<T, \mathrm{~W}<\mathrm{cQ}, I_{e}<\mathrm{I}_{\mathrm{p}}, \text { and full amount made after } \mathrm{t}=\mathrm{M}\right\} \\
& E_{4}=\left\{T \mid 0<\mathrm{M} \leq t_{d}<T, \mathrm{~W} \geq \mathrm{cQ}, I_{e}<\mathrm{I}_{\mathrm{p}}, \text { and full amount made at } \mathrm{t}=\mathrm{M}\right\} \\
& E_{5}=\left\{T \mid 0<t_{d}<\mathrm{M} \leq T, \mathrm{~W}<\mathrm{cQ}, I_{e}<\mathrm{I}_{\mathrm{p}}, \text { partiallly and rest amount paid continuosly }\right\} \\
& E_{6}=\left\{T \mid 0<t_{d}<\mathrm{M} \leq T, \mathrm{~W}<\mathrm{cQ}, I_{e}<\mathrm{I}_{\mathrm{p}}, \text { partiallly and rest amount second shippment }\right\} \\
& E_{7}=\left\{T \mid 0<t_{d}<\mathrm{M} \leq T, \mathrm{~W}<\mathrm{cQ}, I_{e}<\mathrm{I}_{\mathrm{p}}, \text { and full amount made after } \mathrm{t}=\mathrm{M}\right\} \\
& E_{8}=\left\{T \mid 0<t_{d}<\mathrm{M} \leq T, \mathrm{~W} \geq \mathrm{cQ}, I_{e}<\mathrm{I}_{\mathrm{p}}, \text { and full amount made at } \mathrm{t}=\mathrm{M}\right\} \\
& E_{9}=\left\{T \mid 0<t_{d}<T \leq M \text { and } I_{e}<\mathrm{I}_{\mathrm{p}}\right\} \\
& E_{10}=\left\{T \mid 0<\mathrm{M} \leq t_{d}<T \text { and } I_{e} \geq \mathrm{I}_{\mathrm{p}}\right\} \\
& E_{11}=\left\{T \mid \text { if } 0<t_{d}<M \leq T \text { and } I_{e} \geq \mathrm{I}_{\mathrm{p}}\right\} \\
& E_{12}=\left\{T \mid 0<t_{d}<T \leq M \text { and } I_{e} \geq \mathrm{I}_{\mathrm{p}}\right\}
\end{aligned}
$$

and define the characteristic functions as

$$
\phi_{j}(t)=\left\{\begin{array}{ll}
1 & T \in E_{j} \\
0 & T \in E_{j}^{c}
\end{array} \quad j=1 \ldots 12,\right.
$$

and also let

$$
\begin{aligned}
& H_{1}=\frac{1}{T}\left(A+h\left\{\frac{D t_{d}^{2}}{2}+\frac{D}{\theta^{2}}\left(e^{\theta\left(T-t_{d}\right)}-1\right)\left(\theta t_{d}+1\right)-\left(T-t_{d}\right)\right\}+c D\left(t_{d}-T+\frac{1}{\theta}\left(e^{\theta\left(T-t_{d}\right)}-1\right)\right)\right) \\
& H_{k+1}=X_{k} \phi_{k}(t), \quad k=1, \ldots, 12
\end{aligned}
$$

where

$$
\begin{aligned}
& X_{1}=A P_{1.1 .1 .1 .(a)}(\mu, T)-H_{1}, X_{2}=A P_{1.1 .1 .1 .(b)}(\mu, T)-H_{1}, X_{3}=A P_{1.1 .1 .2}(\mu, T)-H_{1}, X_{4}=A P_{1.1 .2}(\mu, T)-H_{1}, \\
& X_{5}=A P_{1.2 .11 .(a)}(\mu, T)-H_{1}, X_{6}=A P_{1.2 .11 .(b)}(\mu, T)-H_{1}, X_{7}=A P_{1.2 .1 .2}(\mu, T)-H_{1}, X_{8}=A P_{1.2 .2}(\mu, T)-H_{1}, \\
& X_{9}=A P_{1.3}(\mu, T)-H_{1}, X_{10}=A P_{2.1}(\mu, T)-H_{1}, X_{11}=A P_{2.2}(\mu, T)-H_{1}, X_{12}=A P_{2.3}(\mu, T)-H_{1},
\end{aligned}
$$


The Profit function in Eq. (29) can be reduced to collective form with the help of Eq. (30) to Eq. (45), as follows:

$$
A P(\mu, T)=\left(\sum_{k=1}^{12} H_{k+1}\right)-H_{1}
$$

\section{Fuzzy Model}

Due to fuzziness, the decision maker unable to determine the exact value of the parameters in business environments, therefore the approximate values of the parameters are considered. In this model, deteriorating rate $\theta=\tilde{\theta}$ and demand rate $D=\tilde{D}$ are considered in fuzzy environment. By substituting $\theta=\tilde{\theta}$ and $D=\tilde{D}=\tilde{a}-\tilde{b} p$ in Eq. (38), the crisp model would convert into fuzzy model as

$$
\widetilde{A P}(\mu, T)=\left(\sum_{k=1}^{12} \tilde{H}_{k+1}\right)-\tilde{H}_{1}
$$

As demand function is taken to be triangular fuzzy number, therefore $\widetilde{A P}(\mu, T)$ is also triangular fuzzy number as

$$
\begin{aligned}
& \widetilde{A P}(\mu, T)=\left(A P_{1}, A P_{2}, A P_{3}\right) \\
& \text { where } A P_{i}=\left(\sum_{k=1}^{12} H_{(k+1)_{i}}\right)-H_{1_{4-i}}, i=1,2,3 \\
& \tilde{H}_{k}=\left(H_{k_{1}}, H_{k_{2}}, H_{k_{3}}\right) \text { and } k=1, \ldots, 13 \\
& H_{1_{j}}=\frac{1}{T}\left(A+c D_{j}\left(t_{d}-T+\frac{1}{\theta_{4-j}}\left(e^{\theta_{j}\left(T-t_{d}\right)}-1\right)\right)+h\left\{\frac{D_{j} t_{d}^{2}}{2}+\frac{D_{j}}{\theta_{4-j}^{2}}\left(e^{\theta_{j}\left(T-t_{d}\right)}-1\right)\left(\theta_{j} t_{d}+1\right)-\left(T-t_{d}\right)\right\}\right) \\
& H_{2_{j}}=\frac{1}{T}\left(D_{j}\left(T-B_{1_{4-j}}\right) p+\frac{1}{2} D_{j}\left(T-B_{1_{4-j}}\right)^{2} p I_{e}\right) \phi_{1}(t) \\
& H_{3_{j}}=\frac{1}{T}\left(D_{j}\left(T-B_{2_{4-j}}\right) p+\frac{1}{2} D_{j}\left(T-B_{2_{4-j}}\right)^{2} p I_{e}\right) \phi_{2}(t) \\
& H_{4_{j}}=\frac{1}{T}\left(D_{j}\left(T-B_{3_{4-j}}\right) p+\frac{1}{2} D_{j}\left(T-B_{3_{4-j}}\right)^{2} p I_{e}\right) \phi_{3}(t) \\
& H_{5_{j}}=\frac{1}{T}\left(D_{j}(T-M) p\left\{1+\frac{1}{2}(T-M) I_{e}\right\}+\left(W_{j}-Q_{4-j} c\right)\left\{1+(T-M) I_{e}\right\}\right) \phi_{4}(t) \\
& H_{6_{j}}=\frac{1}{T}\left(D_{j}\left(T-B_{1_{4-j}}\right) p+\frac{1}{2} D_{j}\left(T-B_{1_{4-j}}\right)^{2} p I_{e}\right) \phi_{5}(t) \\
& H_{7_{j}}=\frac{1}{T}\left(D_{j}\left(T-B_{2_{4-j}}\right) p+\frac{1}{2} D_{j}\left(T-B_{2_{4-j}}\right)^{2} p I_{e}\right) \phi_{6}(t) \\
& H_{8_{j}}=\frac{1}{T}\left(D_{j}\left(T-B_{3_{4-j}}\right) p+\frac{1}{2} D_{j}\left(T-B_{3_{4-j}}\right)^{2} p I_{e}\right) \phi_{7}(t) \\
& H_{9_{j}}=\frac{1}{T}\left(D_{j}(T-M) p\left\{1+\frac{1}{2}(T-M) I_{e}\right\}+\left(W_{j}-Q_{4-j} c\right)\left\{1+(T-M) I_{e}\right\}\right) \phi_{8}(t)
\end{aligned}
$$




$$
\begin{aligned}
& H_{10_{j}}=\frac{1}{T}\left(\left(D_{j} T p-Q_{4-j} c\right)+\frac{1}{2} D_{j} T^{2} p+D_{j} T p\left(1+\frac{1}{2} T I_{e}\right) I_{e}(M-T)\right) \phi_{9}(t) \\
& H_{11_{j}}=\frac{1}{T}\left(\left(D_{j} T p-Q_{4-j} c\right)+\frac{1}{2} D_{j} M^{2} p I_{e}+W_{j} I_{e}(T-M)+\frac{1}{2} D_{j} p(T-M)^{2} I_{e}-Q_{4-j} c(T-M) I_{p}\right) \phi_{10}(t) \\
& H_{12_{j}}=\frac{1}{T}\left(\left(D_{j} T p-Q_{4-j} c\right)+\frac{1}{2} D_{j} M^{2} p I_{e}+W_{j} I_{e}(T-M)+\frac{1}{2} D_{j} p(T-M)^{2} I_{e}-Q_{4-j} c(T-M) I_{p}\right) \phi_{11}(t) \\
& H_{13_{j}}=\frac{1}{T}\left(\left(D_{j} T p-Q_{4-j} c\right)+\frac{1}{2} D_{j} T^{2} p+D_{j} T p\left(1+\frac{1}{2} T I_{e}\right) I_{e}(M-T)\right) \phi_{12}(t) \\
& W_{j}=D_{j} M p+\frac{1}{2} D_{j} M^{2} p I_{e} \\
& Q_{j}=D_{j}\left(t_{d}+\frac{1}{\theta_{4-j}}\left(e^{\theta_{j}\left(T-t_{d}\right)}-1\right)\right) \\
& B_{1_{j}}=M+\frac{2\left(c Q_{j}-W_{4-j}\right)}{2 D_{4-j} p-\left(c Q_{j}-W_{4-j}\right) I_{p}} \\
& B_{2_{j}}=\frac{1}{D_{4-j} p I_{e}}\left\{-D_{4-j} p+D_{j} p I_{e} M+Q_{j} c I_{p}-I_{p} W_{4-j}+\left(\left(D_{j} p-Q_{4-j} c I_{p}+W_{j} I_{e}\right)^{2}+2 D_{j} p Q_{j} c I_{e}\right)^{\frac{1}{2}}\right\} \\
& B_{3_{j}}=\frac{1}{D_{4-j} p I_{e}}\left\{-D_{4-j} p+D_{j} p I_{e} M+Q_{j} c I_{p}-I_{e} W_{4-j}+\left(\left(W_{4-j} I_{e}-Q_{4-j} c I_{p}+D_{j} p\right)^{2}+2 D_{j} p Q_{j} c I_{e}\right)^{\frac{1}{2}}\right\} \\
& D_{j}=a_{j}-p b_{(4-j)} \text { and } p=\mu c
\end{aligned}
$$

Now defuzzify the fuzzy profit function by, using the signed distance method, measured from $\widetilde{A P}$ to $\tilde{0}$

$$
A P_{d}(T, \mu)=\frac{1}{4}\left[A P_{1}+2 A P_{2}+A P_{3}\right]
$$

\section{Solution Procedure}

To determine the optimal values of $\mu$ and $T$, differentiate partially the profit function, $A P_{d}(\mu, T)$ with respect to $\mu$ and $T$ and equating to zero, we obtain:

$$
\begin{aligned}
& \frac{\partial A P_{d}(\mu, T)}{\partial \mu}=0 \\
& \text { and } \frac{\partial A P_{d}(\mu, T)}{\partial T}=0
\end{aligned}
$$

Solving the Eq. (63) and Eq. (64) simultaneously we get obtain the optimal value of $\mu$ and T. The sufficient conditions for the profit maximization are as follows 


$$
\begin{aligned}
& \frac{\partial^{2} A P_{d}(\mu, T)}{\partial \mu^{2}}<0 \text { and } \frac{\partial^{2} A P_{d}(\mu, T)}{\partial T^{2}}<0 \\
& \frac{\partial^{2} A P_{d}(\mu, T)}{\partial T^{2}} \frac{\partial^{2} A P_{d}(\mu, T)}{\partial \mu^{2}}-\frac{\partial^{2} A P_{d}(\mu, T)}{\partial T \partial \mu} \frac{\partial^{2} A P_{d}(\mu, T)}{\partial \mu \partial T}>0
\end{aligned}
$$

The profit functions of the present problem under various cases are highly non-linear and too complicated to solve. Further also it is not easy to show their concavity mathematically, alternatively, we have shown the concavity of these profit functions graphically for all the cases and sub cases with the help of computer software MATLAB. Similarly, the optimal values of various decision variables i.e. mark up rate and cycle length is determined with the help of MS- Excel's solver which uses the GRG2 algorithm.

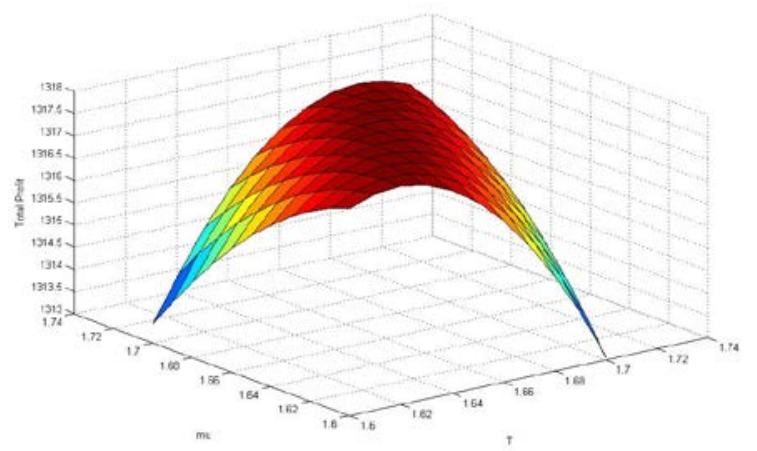

Fig. 13. Optimal Total Profit versus $T$ and $\mu$

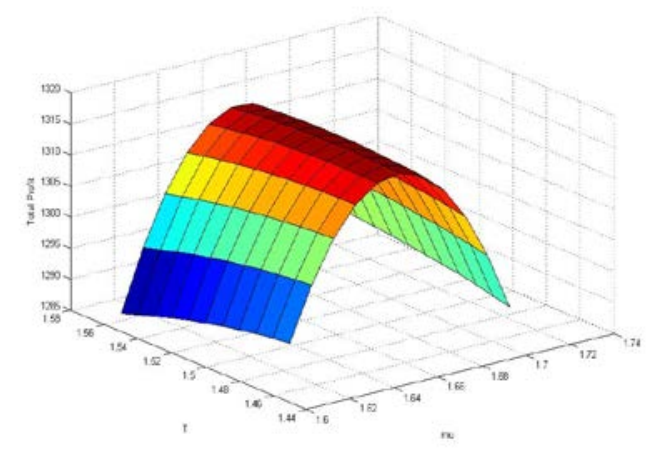

Fig. 14. Optimal Total Profit versus $T$ and $\mu$

\section{Special Case:}

If we assume $a_{1}=a_{2}=a_{3}=a, b_{1}=b_{2}=b_{3}=b$ and $\theta_{1}=\theta_{2}=\theta_{3}=\theta$ and substitute in Eq. (62), then $A P_{d}(\mu, T)$ becomes the crisp total profit function i.e.

$$
A P_{d}(T, \mu)=\left(\sum_{k=1}^{12} H_{k+1}\right)-H_{1}=A P(T, \mu)
$$

That is, the fuzzy case becomes the crisp case.

\section{When $t_{d}=0$ (deterioration is instantaneous)}

Then, the total profit per unit time reduced to

$$
A P(\mu, T)=\left\{\begin{array}{cc}
A P_{1.2 .1 .1 .(a)}(\mu, T) & \text { if } 0<\mathrm{M} \leq T, \mathrm{~W}<\mathrm{cDT}, I_{e}<\mathrm{I}_{\mathrm{p}}, \text { partiallly and rest amount paid continuosly } \\
A P_{1.2 .1 .1 .(b)}(\mu, T) & \text { if } 0<\mathrm{M} \leq T, \mathrm{~W}<\mathrm{cDT}, I_{e}<\mathrm{I}_{\mathrm{p}}, \text { partiallly and rest amount second shippment } \\
A P_{1.2 .1 .2}(\mu, T) & \text { if } 0<\mathrm{M} \leq T, \mathrm{~W}<\mathrm{CDT}, I_{e}<\mathrm{I}_{\mathrm{p}} \text {, and full amount made after } \mathrm{t}=\mathrm{M} \\
A P_{1.2 .2}(\mu, T) & \text { if } 0<\mathrm{M} \leq T, \mathrm{~W} \geq \mathrm{cDT} \text { and } I_{e}<\mathrm{I}_{\mathrm{p}} \\
A P_{1.3}(\mu, T) & \text { if } 0<\mathrm{T} \leq M \text { and } I_{e}<\mathrm{I}_{\mathrm{p}} \\
A P_{2.2}(\mu, T) & \text { if } 0<M \leq T \text { and } I_{e} \geq \mathrm{I}_{\mathrm{p}} \\
A P_{2.3}(\mu, T) & \text { if } 0<M \leq T \text { and } I_{e} \geq \mathrm{I}_{\mathrm{p}}
\end{array}\right.
$$

The comparison between the profit functions given by Eq. (21) and Eq. (68) shows that inventory model with non instantaneous deteriorating items under permissible delay in payment is more generalized than the inventory model with instantaneous deteriorating items under permissible delay in payment. 


\section{Algorithm}

The procedure for determining the optimal values of decision variables are as follows:

For $I_{e}<I_{p}$

Step 1: For event $E_{1}$, determine $\mu^{*}$, and $T^{*}$ from Eq. (63) and Eq. (64). If $\mu^{*}$ and $T^{*}$ are in $E_{1}$ then calculate $A P_{d}\left(\mu^{*}, T^{*}\right)$ from (62), this gives $A P_{(d) \text { 1.1.1.1.(a) }}\left(\mu^{*}, T^{*}\right)$. Otherwise go to step 2.

Step 2: For event $E_{2}$, determine $\mu^{*}$ and $T^{*}$ from Eq. (63) and Eq. (64). If $\mu^{*}$ and $T^{*}$ are in $E_{2}$ then calculate

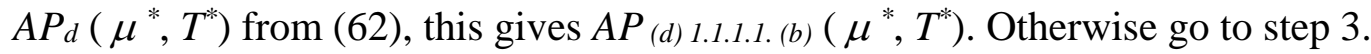

Step 3: For event $E_{3}$, determine $\mu^{*}$ and $T^{*}$ from Eq. (63) and Eq. (64). If $\mu^{*}$ and $T^{*}$ are in $E_{3}$ then calculate $A P_{d}\left(\mu^{*}, T^{*}\right)$ from (62), this gives $A P_{(d)}$ 1.1.1.2 $\left(\mu^{*}, T^{*}\right)$. Otherwise go to step 4.

Step 4: For event $E_{1}$, determine $\mu^{*}$, and $T^{*}$ from Eq. (63) and Eq. (64). If $\mu^{*}$ and $T^{*}$ are in $E_{1}$ then calculate $A P_{d}\left(\mu^{*}, T^{*}\right)$ from (62), this gives $A P(d) 1.1 .2\left(\mu^{*}, T^{*}\right)$. Otherwise go to step 5.

Step 5: For event $E_{5}$, determine $\mu^{*}$, and $T^{*}$ from Eq. (63) and Eq. (64). If $\mu^{*}$ and $T^{*}$ are in $E_{5}$ then calculate $A P_{d}\left(\mu^{*}, T^{*}\right)$ from (62), this gives $A P_{(d) \text { 1.2.1.1. (a) }}\left(\mu^{*}, T^{*}\right)$. Otherwise go to step 6.

Step 6: For event $E_{6}$, determine $\mu^{*}$ and $T^{*}$ from Eq. (63) and Eq. (64). If $\mu^{*}$ and $T^{*}$ are in $E_{6}$ then calculate $A P_{d}\left(\mu^{*}, T^{*}\right)$ from (62), this gives $A P$ (d) 1.2.1.1. (b) $\left(\mu^{*}, T^{*}\right)$. Otherwise go to step 7.

Step 7: For event $E_{7}$, determine $\mu^{*}$ and $T^{*}$ from Eq. (63) and Eq. (64). If $\mu^{*}$ and $T^{*}$ are in $E_{7}$ then calculate $A P_{d}\left(\mu^{*}, T^{*}\right)$ from (62), this gives $A P_{(d) 1.2 .1 .2}\left(\mu^{*}, T^{*}\right)$. Otherwise go to step 8.

Step 8: For event $E_{8}$, determine $\mu^{*}$, and $T^{*}$ from Eq. (63) and Eq. (64). If $\mu^{*}$ and $T^{*}$ are in $E_{8}$ then calculate $A P_{d}\left(\mu^{*}, T^{*}\right)$ from (62), this gives $A P(d) 1.2 .2\left(\mu^{*}, T^{*}\right)$. Otherwise go to step 9.

Step 9: For event $E_{9}$, determine $\mu^{*}$ and $T^{*}$ from Eq. (63) and Eq. (64). If $\mu^{*}$ and $T^{*}$ are in $E_{9}$ then calculate $A P_{d}\left(\mu^{*}, T^{*}\right)$ from (62), this gives $A P(d) 1.3\left(\mu^{*}, T^{*}\right)$. Otherwise go to step 10 .

For $I_{e} \geq I_{p}$

Step 10: For event $E_{10}$, determine $\mu^{*}$ and $T^{*}$ from Eq. (63) and Eq. (64). If $\mu^{*}$ and $T^{*}$ are in $E_{10}$ then calculate $A P_{d}\left(\mu^{*}, T^{*}\right)$ from (62), this gives $A P_{(d) 2.1}\left(\mu^{*}, T^{*}\right)$. Otherwise go to step 11.

Step 11: For event $E_{11}$, determine $\mu^{*}$, and $T^{*}$ from Eq. (63) and Eq. (64). If $\mu^{*}$ and $T^{*}$ are in $E_{11}$ then calculate $A P_{d}\left(\mu^{*}, T^{*}\right)$ from (62), this gives $A P(d) 2.2\left(\mu^{*}, T^{*}\right)$. Otherwise go to step 12.

Step 12: For event $E_{12}$, determine $\mu^{*}$, and $T^{*}$ from Eq. (63) and Eq. (64). If $\mu^{*}$ and $T^{*}$ are in $E_{12}$ then calculate $A P_{d}\left(\mu^{*}, T^{*}\right)$ from (62), this gives $A P(d) 2.3\left(\mu^{*}, T^{*}\right)$. Otherwise go to step1.

The optimal solution of the inventory system can be found by comparing the total profits of all the cases. Hence the optimal total profit of the system is given by

$$
A P_{d}\left(\mu^{*}, T^{*}\right)=\max \left[A P_{d(1)}\left(\mu^{*}, T^{*}\right), A P_{d(2)}\left(\mu^{*}, T^{*}\right)\right]
$$

\section{Numerical Examples}

The proposed model of the inventory system has been illustrated with the help of two hypothetical numerical examples and the data have been depicted in Table 1. Both the examples have been solved by using the proposed algorithm to determine the optimal values of mark up rate $(\mu)$, selling price $(p)$, Breakeven point $\left(B_{i}\right)$, cycle length $(T)$, ordering quantity $(Q)$ along with the optimal profit of the system for all the possible cases and sub-cases. The results have been shown in Table 2. 
Table 1

Values of parameters of different examples

\begin{tabular}{|c|c|c|c|c|c|c|c|c|c|c|}
\hline Example & $\begin{array}{c}A \\
\text { (in\$) } \\
\end{array}$ & $\begin{array}{c}h \\
(\text { in } \$)\end{array}$ & $\theta$ & $\tilde{a}$ & $\tilde{b}$ & $t_{d}$ & C & $\begin{array}{c}I_{e} \\
\text { (per \$) }\end{array}$ & $\begin{array}{c}I_{p} \\
\text { (per \$) }\end{array}$ & $\begin{array}{c}M \\
\text { (days) }\end{array}$ \\
\hline 1. $I_{e}<I_{p}$ & 150 & 10 & $(0.08,0.1,0.14)$ & $(145,150,155)$ & $(0.06,0.07,0.08)$ & 0.2 & 100 & 0.12 & 0.15 & $\begin{array}{l}30 / 365 \\
=0.082\end{array}$ \\
\hline 2. $I_{e} \geq I_{p}$ & 150 & 10 & $(0.08,0.1,0.14)$ & $(145,150,155)$ & $(0.06,0.07,0.08)$ & 0.2 & 100 & 0.2 & 0.15 & $\begin{array}{l}30 / 365 \\
=0.082\end{array}$ \\
\hline
\end{tabular}

Table 2

Result of Example 1 and 2 for different cases, sub cases and scenarios

\begin{tabular}{|c|c|c|c|c|c|c|c|c|c|c|c|}
\hline Section & Case & $\begin{array}{l}\text { Sub- } \\
\text { case }\end{array}$ & Scenarios & $\mu$ & $T$ & $B$ & $W_{i}$ & $p=\mu c$ & $Q$ & Profit & Remark \\
\hline \multirow{9}{*}{$I_{e}<I_{p}$} & \multirow{4}{*}{1.1} & \multirow{3}{*}{1.1 .1} & 1.1.1.1.a & 1.50 & 1.23 & 0.57 & 2481.06 & 150 & 45 & 1334.52 & \multirow{9}{*}{ Scenario1.1.1.1.b } \\
\hline & & & 1.1.1.1.b & 1.48 & 1.02 & 0.47 & 2237.85 & 148 & 37 & 1381.43 & \\
\hline & & & 1.1.1.2 & 1.41 & 0.97 & 0.51 & 2153.74 & 141 & 31 & 1276.09 & \\
\hline & & 1.1 .2 & - & 1.43 & 0.94 & - & 2075.34 & 143 & 20 & 1235.87 & \\
\hline & \multirow{4}{*}{1.2} & \multirow{3}{*}{1.2 .1} & 1.2.1.1.a & 1.47 & 0.86 & 0.54 & 2562.61 & 147 & 35 & 1237.65 & \\
\hline & & & 1.2.1.1.b & 1.42 & 0.73 & 0.45 & 2407.25 & 142 & 26 & 1187.65 & \\
\hline & & & 1.2.1.2 & 1.38 & 0.53 & 0.42 & 2217.53 & 138 & 23 & 948.35 & \\
\hline & & 1.2 .2 & - & 1.41 & 0.76 & - & 2147.07 & 141 & 21 & 1176.54 & \\
\hline & 1.3 & & & 1.49 & $M$ & - & - & 149 & 25 & 1043.47 & \\
\hline \multirow{3}{*}{$I_{e} \geq I_{p}$} & 2.1 & - & - & 1.58 & 1.07 & 0.73 & 3547.34 & 158 & 42 & 1457.73 & \multirow{3}{*}{ Scenario 2.1} \\
\hline & 2.2 & - & - & 1.52 & 0.65 & - & 2467.07 & 152 & 34 & 1345.67 & \\
\hline & 2.3 & - & - & 1.48 & $M$ & - & - & 148 & 27 & 1136.27 & \\
\hline
\end{tabular}

Using the proposed algorithm the results are as follows:

For $I_{e}<I_{p}$

$\mu_{1}^{*}=1.48, p_{1}^{*}=\$ 148, B_{1}^{*}=0.47$ year, $T_{1}^{*}=1.02$ year, $Q_{1}^{*}=37$ units and total profit $=\$ 1381.43$ (Scenario 1.1.1.1.b)

For $I_{e} \geq I_{p}$

$\mu_{2}^{*}=1.58, p_{2}^{*}=\$ 158, B_{2}^{*}=0.73$ year, $T_{2}^{*}=1.07$ year, $Q_{2}^{*}=42$ units and total profit $=\$ 1457.73$ (Case 2.1)

\section{Sensitivity Analysis}

To study the effects of changes of different parameters [like, $A$ (ordering cost), $a, b$ (location parameter of demand), $h$ (holding cost), $c$ (unit purchase cost of retailer), $M$ (Permissible delay in payment) on the optimal policies, sensitivity analyses have been performed numerically. These analyses have been carried out by changing $-20 \%$ to $+20 \%$ for one parameter keeping other parameters as same. The results of these analyses have been displayed in Table 3.

From Table 3, the following inferences can be made:

$>$ One can easily observe that with the increase in value of ordering cost $(A)$, the optimal cycle length $(T)$, optimal order quantity $(Q)$ increases; but the total profit $(A P)$ decreases.

With the increase in the holding cost $(h)$, the total profit $(A P)$ decreases as there is an increase in carrying cost.

With the increase in the value of $(a)$, the total profit $(A P)$ increases whereas as the value of $(b)$ increases, the total profit $(A P)$ decreases. 
As the cost per unit $(c)$ increases, there is a decrement in the value of total profit $(A P)$. This reveals the natural trend of cost-profit analysis.

It is clearly observe that as the credit period $(M)$ increases, both optimal order quantity $(Q)$ and total profit $(A P)$ increases.

$>$ It is observed from table 3 , as the deterioration rate $(\boldsymbol{\theta})$ increases then there is significant decrease in total profit $(A P)$ \& increase in order quantity $(Q)$ because a rise in deterioration rate $(\theta)$ causes an increase in the cost of deteriorated units, which ultimately increase the total cost.

From the table 3 it is clearly visible that with an increase in the value of $t_{d}$, it can be observed that cycle length $(T)$, order quantity $(Q)$ and total profit $(A P)$ increases. This clearly indicates the positive impact of non-instantaneous deteriorating items in the inventory modelling. As the period for non-deterioration $\left(t_{d}\right)$ increases, the deterioration cost for items decreases which accounts for larger profits for the company.

Table 3

Effect of changes in the system parameters

\begin{tabular}{|c|c|c|c|c|c|c|}
\hline Parameters & \% changes & $\mu$ & $T$ & $B$ & $Q$ & Profit \\
\hline \multirow{4}{*}{$A$} & $-20 \%$ & -1.03 & -21.39 & -28.32 & -26.64 & 4.56 \\
\hline & $-10 \%$ & -0.48 & -12.03 & -15.54 & -14.73 & 1.43 \\
\hline & $10 \%$ & 0.75 & 19.58 & 18.59 & 18.23 & -0.86 \\
\hline & $20 \%$ & 1.53 & 38.84 & 37.15 & 35.31 & -2.36 \\
\hline \multirow{4}{*}{$a$} & $-20 \%$ & -13.23 & 28.64 & 47.65 & -35.08 & -75.34 \\
\hline & $-10 \%$ & -6.17 & 11.75 & 23.05 & -15.69 & -42.81 \\
\hline & $10 \%$ & 6.13 & -9.23 & -15.86 & 15.02 & 49.83 \\
\hline & $20 \%$ & 12.56 & -12.45 & -24.63 & 29.65 & 93.78 \\
\hline \multirow{4}{*}{$b$} & $-20 \%$ & 4.04 & 58.53 & 15.07 & 53.91 & 17.89 \\
\hline & $-10 \%$ & 3.09 & 34.04 & -23.09 & 32.76 & 13.57 \\
\hline & $10 \%$ & -3.18 & -34.98 & -33.11 & -33.05 & -13.90 \\
\hline & $20 \%$ & -3.92 & -57.31 & 9.87 & -50.61 & -17.07 \\
\hline \multirow{4}{*}{$h$} & $-20 \%$ & -0.19 & 7.24 & 7.72 & 7.36 & 4.72 \\
\hline & $-10 \%$ & -0.08 & 3.34 & 3.56 & 3.43 & 1.83 \\
\hline & $10 \%$ & 0.51 & -2.76 & -3.18 & -3.69 & -1.75 \\
\hline & $20 \%$ & 0.85 & -6.43 & -5.83 & -6.87 & -4.21 \\
\hline \multirow{4}{*}{$C$} & $-20 \%$ & 15.37 & 5.63 & -29.63 & 34.27 & 56.43 \\
\hline & $-10 \%$ & 7.42 & 2.27 & -13.54 & 15.53 & 30.25 \\
\hline & $10 \%$ & -5.83 & -2.84 & 13.82 & -14.67 & -35.04 \\
\hline & $20 \%$ & -12.75 & -5.82 & 28.32 & -37.92 & -73.25 \\
\hline \multirow{4}{*}{$M$} & $-20 \%$ & 0.02 & 1.33 & 0.99 & 0.93 & -1.05 \\
\hline & $-10 \%$ & 0.01 & 0.65 & 0.49 & 0.46 & -0.52 \\
\hline & $10 \%$ & -0.01 & -0.63 & -0.46 & -0.44 & 0.52 \\
\hline & $20 \%$ & -0.02 & -1.23 & -0.90 & -0.86 & 1.03 \\
\hline \multirow{4}{*}{$\theta$} & $-20 \%$ & 0.08 & 10.17 & 7.47 & -0.081 & 31.80 \\
\hline & $-10 \%$ & 0.05 & 6.90 & 5.23 & -0.078 & 23.53 \\
\hline & $10 \%$ & -0.14 & -13.43 & 9.55 & 0.083 & -46.40 \\
\hline & $20 \%$ & -0.18 & -16.42 & 11.47 & 0.086 & -58.29 \\
\hline \multirow{4}{*}{$t_{d}$} & $-20 \%$ & -051 & -30.48 & -23.62 & -0.15 & -18.54 \\
\hline & $-10 \%$ & -0.53 & -33.93 & -22.45 & -0.12 & -10.24 \\
\hline & $10 \%$ & 0.61 & 36.02 & 21.33 & 0.12 & 11.91 \\
\hline & $20 \%$ & 0.71 & 38.62 & 21.29 & 0.13 & 20.72 \\
\hline
\end{tabular}

\section{Concluding Remarks}

In this study, a fuzzy inventory model for non-instantaneous deteriorating items under conditions of permissible delay in payments has been presented. Further, this paper also considers price-dependent demand and the possibility of higher interest earn rate than interest payable rate. The present paper is a generalized model under permissible delay in payment as it considers all the possible financial scenarios. The objective of this study is to determine the retailer's optimal replenishment policies using the 
proposed algorithm, which maximizes the total profit per unit time. The study concludes with a numerical example and sensitivity analysis of the optimal solution with respect to key parameters of the inventory system so as to provide some important managerial implications. The results exhibit the positive impact of non-instantaneous deteriorating items in the inventory modeling. Also, the retailer's profit increases as the supplier delays the period to settle the payments.

This paper may also be extended for stock-dependent demand, two-level trade credit, cash discount and many other realistic situations.

\section{Acknowledgment}

The first author would like to acknowledge the support of the Research Grant No.: RC/R\&D/2014/6820, provided by the University of Delhi, Delhi, India for accomplishing this research. The third author would like to thank University Grant Commission (UGC) for providing the Non - NET fellowship to accomplish the research.

\section{References}

Aggarwal, S. P., \& Jaggi, C. K. (1995). Ordering policies of deteriorating items under permissible delay in payments. Journal of the Operational Research Society, 46(5), 658-662.

Chang, S. C., Yao, J. S., \& Lee, H. M. (1998). Economic reorder point for fuzzy backorder quantity. European Journal of Operational Research, 109(1), 183-202.

Chang, C. T., Teng, J. T., \& Goyal, S. K. (2008). Inventory lot-size models under trade credits: a review. Asia-Pacific Journal of Operational Research, 25(1), 89-112.

Chang, C. T., Teng, J. T., \& Goyal, S. K. (2010). Optimal replenishment policies for non-instantaneous deteriorating items with stock-dependent demand. International Journal of Production Economics, 123(1), 62-68.

Chen, L. H., \& Ouyang, L. Y. (2006). Fuzzy inventory model for deteriorating items with permissible delay in payment. Applied Mathematics and Computation, 182(1), 711-726.

Cheng, M. C., Chang, C. T., \& Ouyang, L. Y. (2012). The retailer's optimal ordering policy with trade credit in different financial environments. Applied Mathematics and Computation, 218(19), 96239634.

Cohen, M. A. (1977). Joint pricing and ordering policy for exponentially decaying inventory with known demand. Naval Research Logistics Quarterly, 24(2), 257-268.

Dutta, P., Chakraborty, D., \& Roy, A. R. (2005). A single-period inventory model with fuzzy random variable demand. Mathematical and Computer Modelling, 41(8), 915-922.

Dye, C.Y. (2013). The effect of preservation technology investment on a non-instantaneous deteriorating inventory model. Omega, 41(5), $872-880$.

Gani, A. N., \& Maheswari, S. (2010). Supply chain model for the retailer's ordering policy under two levels of delay payments in fuzzy environment. Applied Mathematical Sciences, 4(21-24), 11551164.

Geetha, K. V., \& Uthayakumar, R. (2010). Economic design of an inventory policy for non-instantaneous deteriorating items under permissible delay in payments. Journal of Computational and Applied Mathematics, 233(10), 2492-2505.

Goyal, S. K. (1985). Economic order quantity under conditions of permissible delay in payments. Journal of the Operational Research Society, 36(4), 335-338.

Haley, C. W., \& Higgins, R. C. (1973). Inventory policy and trade credit financing. Management Science, 20(4), 464-471.

Hwang, H., \& Shinn, S. W. (1997). Retailer's pricing and lot sizing policy for exponentially deteriorating products under the condition of permissible delay in payments. Computers \& Operations Research, 24(6), 539-547. 
Jaggi, Chandra K., Goyal, S.K., \& Goel, S. K. (2008). Retailer’s optimal replenishment decisions with credit-linked demand under permissible delay in payments. European Journal of Operational Research, 190(1), 130-135.

Jaggi, C. K., \& Verma, P. (2010). An optimal replenishment policy for non-instantaneous deteriorating items with two storage facilities. International Journal of Services Operations and Informatics, 5(3), 209-230.

Jamal, A. M. M., Sarker, B. R., and Wang, S. (1997). An ordering policy for deteriorating items with allowable shortage, and permissible delay in payment. Journal of the Operational Research Society, 48(8), 826-833.

Kacprzyk, J., \& Stanieski, P. (1982). Long-term inventory policy-making through fuzzy decision-making models. Fuzzy Sets and Systems, 8(2), 117-132.

Kaufmann, A., \& Gupta, M. M. (1991). Introduction to fuzzy arithmetic: theory and applications. Arden Shakespeare.

Kao, C., \& Hsu, W. K. (2002). A single-period inventory model with fuzzy demand. Computers \& Mathematics with Applications, 43(6), 841-848.

Mahata, G. C., \& Mahata, P. (2011). Analysis of a fuzzy economic order quantity model for deteriorating items under retailer partial trade credit financing in a supply chain. Mathematical and Computer Modelling, 53(9), 1621-1636.

Maihami, R., \& Kamalabadi, I. N. (2012). Joint pricing and inventory control for non-instantaneous deteriorating items with partial backlogging and time and price dependent demand. International Journal of Production Economics, 136(1), 116-122.

Maihami, R. \& Kamalabadi, I. N. (2012). Joint control of inventory and its pricing for noninstantaneously deteriorating items under permissible delay in payments and partial backlogging. Mathematical and Computer Modelling, 55(5-6), 1722 - 1733.

Malik, A. K., \& Singh, Y. (2011). An inventory model for deteriorating items with soft computing techniques and variable demand. International Journal of Soft Computing and Engineering, 1(5), 317321.

Molamohamadi, Z., Ismail, N., Leman, Z., \& Zulkifli, N. (2014). Reviewing the literature of inventory models under trade credit contact. Discrete Dynamics in Nature and Society, 2014.

Mukhopadhyay, S., Mukherjee, R. N., \& Chaudhuri, K. S. (2004). Joint pricing and ordering policy for a deteriorating inventory. Computers \& Industrial Engineering, 47(4), 339-349.

Ouyang, L. Y., Wu, K. S., \& Yang, C. T. (2008). Retailer's ordering policy for non-instantaneous deteriorating items with quantity discount, stock-dependent demand and stochastic backorder rate. Journal of the Chinese Institute of Industrial Engineers, 25(1), 62-72.

Park, K. S. (1987). Fuzzy-set theoretic interpretation of economic order quantity. Systems, Man and Cybernetics, IEEE Transactions, 17(6), 1082-1084.

Rong, L. (2011). Two new uncertainty programming models of inventory with uncertain costs. Journal of Information and Computational Science, 8(2), 280-288.

Roy, T. K., \& Maiti, M. (1997). A fuzzy EOQ model with demand-dependent unit cost under limited storage capacity. European Journal of Operational Research, 99(2), 425-432.

Sarkar, S., \& Chakrabarti, T. (2011). An EPQ model with two-component demand under fuzzy environment and Weibull distribution deterioration with shortages. Advances in Operations Research, 2012.

Seifert, D., Seifert, R. W., \& Protopappa-Sieke, M. (2013). A review of trade credit literature: Opportunities for research in operations. European Journal of Operational Research, 231(2), 245256.

Shah, N. H. (1993). A lot-size model for exponentially decaying inventory when delay in payments is permissible. Cahiers du Centre d'études de recherche opérationnelle, 35(1-2), 115-123.

Shah, N. H., Soni, H. N. \& Patel, K. A. (2013). Optimizing inventory and marketing policy for noninstantaneous deteriorating items with generalized type deterioration and holding cost rates. Omega, 41(2), $421-430$. 
Singh, S. R., Kumar, T., \& Gupta, C. B. (2011). A Soft Computing based Inventory Model with Deterioration and Price Dependent Demand. International Journal of Computer Applications, 36(4), $10-17$.

Song, J. S., \& Zipkin, P. (1993). Inventory control in a fluctuating demand environment. Operations Research, 41(2), 351-370.

Soni, H., Shah, N. H., \& Jaggi, C. K. (2010). Inventory models and trade credit: a review. Control and Cybernetics, 9(3), 867-882.

Soni, H., \& Patel, K. (2012). Optimal pricing and inventory policies for non-instantaneous deteriorating items with permissible delay in payment: Fuzzy expected value model. International Journal of Industrial Engineering Computations, 3(3), 281-300.

Syed, J. K., \& Aziz, L. A. (2007). Fuzzy inventory model without shortages using signed distance method. Applied Mathematics \& Information Sciences, 1(2), 203-209.

Uthayakumar, R. \& Valliathal, M. (2011). Fuzzy economic production quantity model for weibull deteriorating items with ramp type of demand. International Journal of International Journal of Strategic Decision Sciences, 2(3), 55-90.

Vujošević, M., Petrović, D., \& Petrović, R. (1996). EOQ formula when inventory cost is fuzzy. International Journal of Production Economics, 45(1), 499-504.

Vijayan, T., \& Kumaran, M. (2008). Inventory models with a mixture of backorders and lost sales under fuzzy cost. European Journal of Operational Research, 189(1), 105-119.

Wee, H. M. (1997). A replenishment policy for items with a price-dependent demand and a varying rate of deterioration. Production Planning \& Control, 8(5), 494-499.

Wee, H. M. (1999). Deteriorating inventory model with quantity discount, pricing and partial backordering. International Journal of Production Economics, 59(1), 511-518.

Wang, X., Tang, W., \& Zhao, R. (2007). Fuzzy economic order quantity inventory models without backordering. Tsinghua Science \& Technology, 12(1), 91-96.

Wu, K. S., Ouyang, L. Y., \& Yang, C. T. (2006). An optimal replenishment policy for non-instantaneous deteriorating items with stock-dependent demand and partial backlogging. International Journal of Production Economics, 101(2), 369-384.

Wu, K. S., Ouyang, L. Y., \& Yang, C. T. (2009). Coordinating replenishment and pricing policies for non-instantaneous deteriorating items with price-sensitive demand. International Journal of Systems Science, 40(12), 1273-1281.

Yao, J. S., \& Chiang, J. (2003). Inventory without backorder with fuzzy total cost and fuzzy storing cost defuzzified by centroid and signed distance. European Journal of Operational Research, 148(2), 401409.

Zadeh, L. A. (1965). Fuzzy sets. Information and control. 8(3), 338-353.

Zimmermann, H. J. (1985). Fuzzy Set Theory and Its Applications. Kluwer-Nijho, Hinghum, Netherlands. 